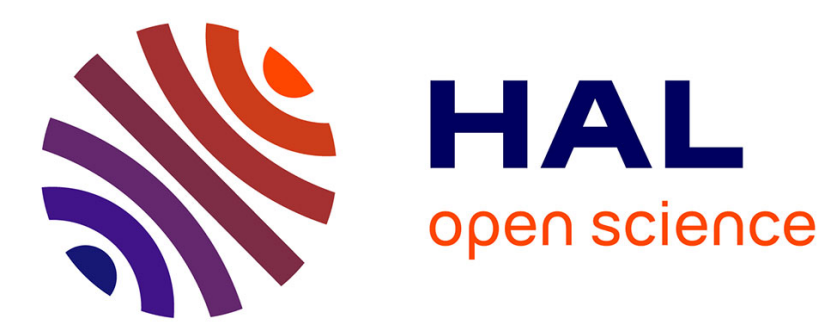

\title{
Contexts and dependencies in the ComMod processes
}

Raphael Mathevet, Martine Antona, Cécile Barnaud, Christine Fourage, Guy Trebuil, Sigrid Aubert

\section{To cite this version:}

Raphael Mathevet, Martine Antona, Cécile Barnaud, Christine Fourage, Guy Trebuil, et al.. Contexts and dependencies in the ComMod processes. Companion modelling, A Participatory Approach Supporting Sustainable Development, Quae, pp.97-116, 2011. cirad-00844600

\section{HAL Id: cirad-00844600 http://hal.cirad.fr/cirad-00844600}

Submitted on 15 Jul 2013

HAL is a multi-disciplinary open access archive for the deposit and dissemination of scientific research documents, whether they are published or not. The documents may come from teaching and research institutions in France or abroad, or from public or private research centers.
L'archive ouverte pluridisciplinaire HAL, est destinée au dépôt et à la diffusion de documents scientifiques de niveau recherche, publiés ou non, émanant des établissements d'enseignement et de recherche français ou étrangers, des laboratoires publics ou privés. 


\title{
Chapter 4
}

\section{Contexts and dependencies in the ComMod processes}

\author{
Raphä̈l Mathevet, Martine Antona, Cécile Barnaud, Christine Fourage, \\ GUY TRÉBUIL AND SIGRID AUBERT
}

The ComMod approach involves the interaction of local actors, heterogeneous social groups with different rationales and interests, and researchers and institutional stakeholders (i.e. donors, sponsors, administrators and experts), whose socio-political rationales and biophysical intervention framework are just as varied. The project, or intervention within this 'group of actors' (Henocque and Denis, 2001) gives rise to dialogue, confrontation, combined construction of the posed problem and its definition, and a description and understanding of processes involved, be they social, economic or environmental. The process may produce new knowledge or technical resources. The pooling of each other's knowledge and the exchanges that take place in the workshops focus on how to access and manage resources, monitor practices, and limit or encourage some of their effects. Here, the expansion of both decentralization and community-based development, the diversity of actors and power asymmetries involved, the quest for legitimacy of the actions of certain stakeholders, the desire to promote the participation of these actors in the analysis and design of the management systems, and the possibity of empowering local stakeholders, together raise a critical question: what role should be given to context?

The ComMod approach creates or is involved in an action arena where participants (individuals, organizations and representatives) interact within a specific context, which is affected by exogenous variables at the time it is implemented. These interactions produce outcomes, decisions or actions, which in turn affect the participants and the action situations as well as some or all of the exogenous variables (see Figure 4.1). The action situation may be defined by a set of variables: the positions of participants, the potential outcomes, the relations between actions and results, the ability to control participants, the type of information generated, and the costs and benefits of the interaction 
products (Ostrom, 2005). The action situation is nothing more than the social environment in which participants interact. The action arena thus defined by the participants and a given action situation is dependent on exogenous factors that may affect its structure. These exogenous variables can be characterized by three dimensions: the institutional dimension (the rules in use), the biophysical dimension (the biophysical attributes involved), and the social dimension (the attributes of the social community in which the action arena takes place). Within this analysis framework, we thus consider that these exogenous variables form the socio-environmental context and the action arena is the intervention context. This gives rise to three sets of questions. When and how should the ComMod approach consider the socio-environmental context? When and how should the ComMod approach consider the intervention context (action arena)? In return, how does the consideration given to these two types of contexts affect the process and its outcomes?

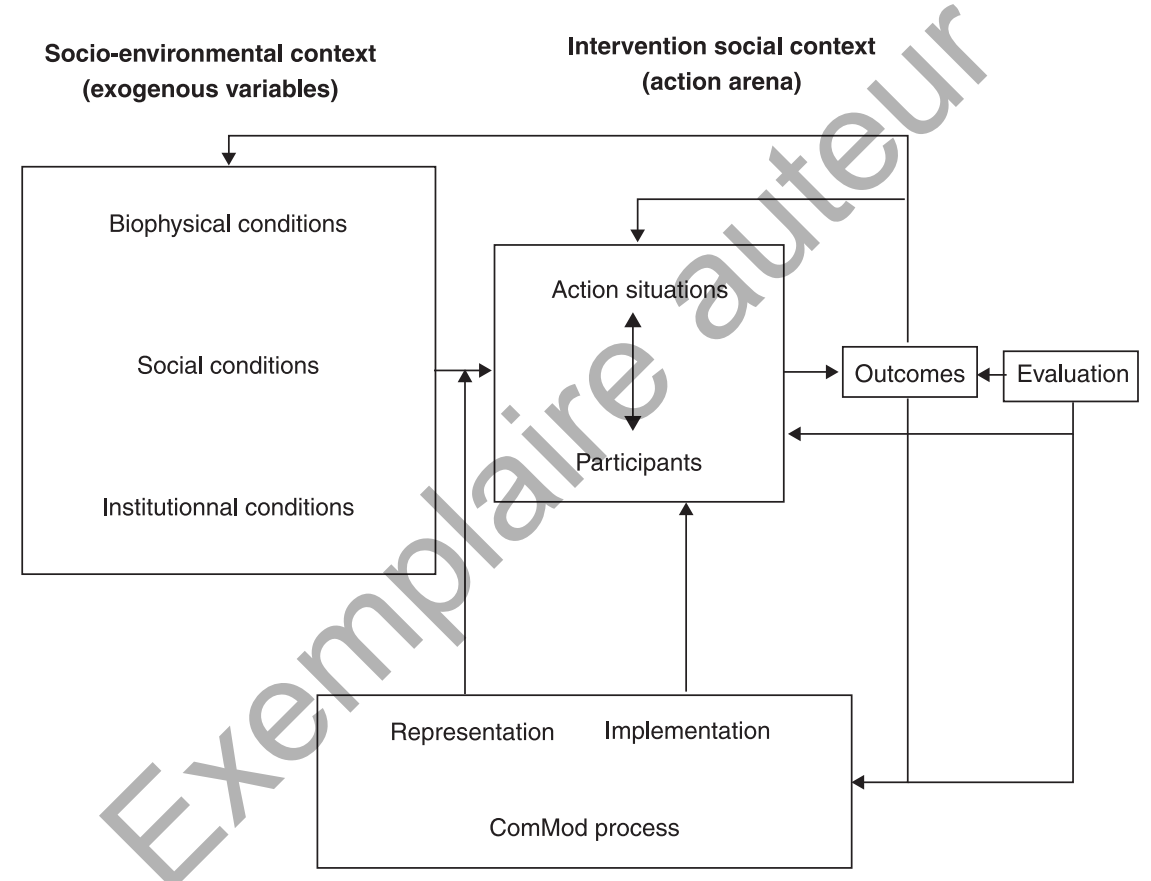

Figure 4.1. Context analysis framework (adapted from Ostrom, 2005).

The ComMod approach can be seen as a process of social interactions, which gradually takes into account the socio-environmental context and, through its flexibility, alters or establishes the intervention context in the process (see Box 4.1). However, the question of whether to consider the initial socio-environmental context and the intervention context before starting the process is the subject of much debate within the ComMod group, as opinions and practices vary. Some members of the group consider that it is important to consider both these contexts from the outset during studies prior to implementation. This initial stage is likely to be highly strategic, as the choice of participants and decisions regarding the intervention procedures are dependent on it and 
give impetus to, or affect, the process outcome. Furthermore, simply focusing attention on the context issue again raises the question regarding the feasibility conditions of the ComMod approach: is it still appropriate or desirable? Others, however, consider that this initial consideration is pointless because of its relative subjectivity and incompleteness and that the approach is a process which, according to the participants involved, is used to set up the socio-environmental context parameters needed to deal with the problem identified and to define, modify and adapt the action arena accordingly.

So consideration will first be given to the social and environmental context and intervention context in the theories relating to the management of socio-ecological systems and in participatory approaches to development and conservation. Then, the tools and methods used to characterize the context in participatory approaches and ComMod approaches will be reviewed. After explaining the nature of the materials analysed and the methodology used, we describe the ComMod approach contexts studied and then discuss: (i) the effects of including or not including the context in the definition of objectives; (ii) the choice of participants; (iii) the influence on project dynamics; (iv) the consequences for decision and action. We finish by discussing the perspectives these results open.

\section{Box 4.1 - The context as generally construed.}

Territorial framework: definition and description of the site scope, its environment, administrative and functional divisions and natural resources.

Historical context: regional history, site history and history of conflicts in the territory concerned.

Socio-economic context: population and land tenure dynamics, dynamics of economic activities and unemployment, and dynamics of the main equipment and infrastructure.

Cultural context: degree of inequality, phallocentrism, individualism and tolerance of uncertainty (risk aversion).

Institutional context: public, sectoral, environmental and land management policies, and the scope of management tools; legal framework, institutional processes, and local, regional, national and international combinations.

Political context: oppositions involved, elections and terms, policy-makers and opinion leaders.

Stakeholders: identification of key stakeholders, interests and relationships, importance and influence of actors and their position within the social network, and power asymmetry.

Social, economic, political, environmental, institutional issues: directly or indirectly linked with the project.

Territorial perspectives: main land planning and management policy guidelines, territorial projects.

Amended from Cicin-Sain and Knecht (1998) 


\section{Trends in the consideration given to the socio- environmental context and intervention social context}

\section{Trends in the understanding of interactions within socio-ecological systems}

Several theoretical changes relating to the management of ecosystems and renewable natural resources argue in favour of taking greater account of the socio-environmental context and intervention social context. The shift from the paradigm of stability and equilibrium as the main regulator of ecosystems (Odum, 1983) to that of adaptability calls for consideration to be given to the spatial and temporal heterogeneity in the functioning of socio-ecological systems, and the need to include the governance of space and resources. Disruptions are common and widespread: ecosystems are open, non-linear and interconnected in the landscape (Barbault, 1997; Kareiva and Wennergren, 1995; Holling, 2001), and socio-ecological systems considered as natural are in fact strongly influenced by human activities on various scales (Allen and Star, 1982; Forman and Godron, 1986; Callicott et al., 1999; Folke and Holling, 1996). The 'flux of Nature' paradigm stresses that we need to know and understand the past and present effects of interactions between human activities and ecosystems (Leopold, 1949; Bertrand, 1978; Mathieu and Jollivet, 1989; Pickett et al., 1992; Primack, 1993). Adaptability in ecosystems is based on maintaining genetic diversity, biological diversity and landscape heterogeneity (Holling, 1978). It also requires the existence of institutions and networks that learn and memorize knowledge and experimentation, create flexibility in solving problems and help to balance the power of interest groups (Santos, 1997; Berkes and Folke, 1998; Berkes et $a l ., 2002)$. For this purpose, it is important to give consideration to the social context and institutions (Folke and Carpenter, 2002; Gumuchian et al., 2003). Ostrom (1990) and Berkes and Folke (1998), in particular, have studied their role in the management of socio-ecological systems.

The analysis of socio-ecological systems systematically faces difficulties in identifying an appropriate, relevant level of analysis to address a given problem (Ostrom, 2005). Understanding the sustainability or resilience of an ecological or a social system involves understanding its background and origins in order to be able to incorporate them and transform them by 'unplanning' and 're-functioning' parts of them (Burnouf, 2008). This consideration of heritage is facilitated by a combination of tools providing a representation of spatial dynamics on different scales, implementing systemic schemes drawn up with local stakeholders and discussing spatial, social and environmental interdependencies (GIS participatory mapping and MAS). However, the breakdown of decisions and actions on different hierarchical decision-making and spatial levels remains difficult to represent and take into account (Berkes et al., 2002). While this may be due to an unclear definition of the scope of the problem and study, the socio-economic contexts of socio-ecological systems are generally very complex, and their scale, limits and content undefined.

So rather than referring to a vague, unspecified context, the conditions of stakeholder actions should be analysed in terms of their perceptions and beliefs and seen in their social network and interactions with others and institutions (Ostrom, 2005; Raynaud, 2006; Bailey, 1969). Beyond the general biophysical and geographical context, the social 
context is characterized by (Moulaert and Mehmood, 2008; Nguinguiri, 2008; Froger, 2006) (see Box 4.1):

- the diversity of stakeholders: diversity of actors and stakeholder groups, and diversity of social values, concerns, justifications and interests

- the plurality of norms: official norms (state), local norms (so-called traditional or customary) and international norms (conventions), etc.

- the aggregation of authority and decision-making centres wholly or partly within or outside the system in question

- 'borderline' actors at the interface of representations or stakeholder groups.

In this social context, social change and adaptation to a changing socio-economic and/or ecological environment thus depends on the stakeholders' ability to handle various systems of rules and establish a new basis for institutional innovation without necessarily removing the old ones (Smouts, 1998; Ostrom, 1990). The understanding of governance thus involves understanding the norms actually implemented (Ostrom, 1990; Olivier de Sardan, 2001). To identify and determine the role of such norms, analysis of the overall socio-political context also increasingly includes a micro-sociological analysis of local actors and organizations in terms of networks and conflicts through an analysis of practices, strategies and interests (Lavigne-Delville et al., 2000). Similarly, issues involving the modes of collective action, regulation and control implemented within organizations according to available resources are studied (Kalaora, 2003; Nguinguiri, 2008).

In this approach, the cultural dimension seems unavoidable and is increasingly included in research or action research projects (Long, 1990; Jiggins and Röling, 2000). As the social learning process takes place in a particular technical and social context allowance should be made for this. Pahl-Wostl et al. (2008) suggested an analytical framework for the cultural context in order to adjust the involvement of local stakeholders. This framework can be divided into four main aspects: perception, rationality, morality and prescription. This analytical framework performs four functions in the project: it identifies a reality that is not spontaneously apparent; gives meaning to this reality; provides value judgements; gives recommendations on how to manage the cultural context of the interactions of local communities with their environments and resources according to the context considered.

The context can thus influence the action context in three ways (Raynaud, 2006):

- the context determines (e.g. attributes of actors directly influencing the action situations)

- the context conditions (e.g. previous actions, margins of manoeuvre reduced because of variations in data outside the action situations)

- the context acts as a general reference (e.g. influence unspecified as dispersed, etc.).

\section{Trends in participatory approaches}

Field projects have produced many methods aimed at understanding the socioenvironmental context and the intervention social context. These methods, which were first focused on technical expertise, have evolved towards consultation of local stakeholders and then towards true social engineering.

In development terms, one of the first approaches was a representation based on the technical development of the green revolution of the 1960s. The input of the context established at the time was essentially technical. Experts and researchers identified the 
technical variables and elements that could increase or improve agricultural productivity (Lavigne-Delville et al., 2000). Limiting factors were then overcome by technical solutions and a transfer of technology with a varying degree of success. On the basis of the many failures observed in this transfer, the vision of taking the context into account through a diagnosis that was too focused on technology was questioned by many authors in the development research field (Lavigne- Delville et al., 2000). This intervention model was replaced in the 1970 s and 1980 s by a socio-environmental context approach based on a systemic approach to farming system research (Collinson, 2000), which identified the social, economic and cultural context of the farmers concerned by development projects. The context study then attempted to understand the functioning of agricultural systems in order to adapt research technologies to local conditions (Collinson, 2000). More disciplines were involved and allowed the analysis of socio-economic and agro-ecological dynamics on different scales (e.g. from the plot, to the farm, land and territory). Despite this progress, little consideration was given to the intervention social context. The role of stakeholder strategies remained marginal. Despite the participation of local populations in the change process, choices were still largely dictated by the technological and economic dimensions and were made by researchers, experts and central policy-makers. Finally, since the 1990s, the widespread use of participatory discourse has led to the intervention social context being taken into account more comprehensively (Chambers, 1983; Chambers et al., 1989). A gradual reversal of the approach has been seen. After the widespread use of rapid rural analysis methods that allowed the views of local people to be taken into account in order to scale innovation transfer more to the local context, approaches have tended towards participatory rural appraisal (McCracken et al., 1988; Chambers, 1994b). Communities are empowered to define their needs so that the diagnosis is the result of a trade-off between stakeholders and experts acting as information providers and/or facilitators of approaches (Olivier de Sardan, 1995). Finally, approaches extended participation to project planning and actions with tools such as participatory learning and action, where the learning of both local stakeholders and researchers is emphasized and objectives are defined by the group rather than beforehand (Pretty, 1995; Scoones and Thompson, 1994), thus contributing to the empowerment of the actors (Pretty, 2003; De Koning, 1995).

The approaches to biodiversity conservation and management of renewable natural resources ${ }^{1}$ showed a similar pattern over the same period (Pimbert and Pretty, 1997). Having promoted the exclusion of local populations from areas to create protected areas (Rodary et al., 2003), these approaches considered the conservation area as the 'society area' (Mathevet and Poulin, 2006), and this called for the social context to be taken into account (Olivier de Sardan, 1995). The traditional institutions were reconsidered and the local communities were seen as the most likely actors to respect the resources because of their dependency and proximity (Berkes et al., 1991). Community approaches developed, particularly in the management of forest resources (Ostrom, 1990) and participation in the implementation of decentralization policies for the management of natural resources with highly heterogeneous results.

\footnotetext{
${ }^{1}$ Guided by the visions and techniques developed through research and development, they are based on the same observation of failures in the nature conservation measures taken and the centralized management of natural resources by governments
} 
Since the 1980s and now under the order of international donors, participatory approaches have thus become widespread (Pimbert and Pretty, 1997). These approaches are based on several assumptions. From the normative standpoint, encouraging individual and social learning is considered to be good for society and citizens in general (Ludwig, 2001; Latour, 1999). The second substantive assumption considers that encouraging the mainstreaming of multiple viewpoints provides a better understanding of issues and improves the identification and selection of suitable solutions (Van den Hove, 2001). Finally, from the instrumental standpoint, encouraging cooperation is considered to facilitate greatly the implementation of solutions and reduce conflicts (Brandon and Wells, 1992). Participatory approaches are thus likely to overcome the opposition between general and specific interests and recognize the role of the procedural negotiated dimension of general interest (Trom, 1999). The participation of local populations thus brings 'experts' and so-called 'lay' visions closer together (Callon et al., 2001). This brings about a change in the very conception of local actors from that of a uniform, indiscriminate and sometimes ignorant and irrational public (the 'villager' or the 'community') to that of a system of composite, plural actors with know-how, knowledge and skills related to their experience and capabilities, and who have the ability to act as 'lay experts' (Boy, 2003; Lascoumes, 2005). These changes are profound because on the one hand, they call into question conventional top-down approaches in the formulation and implementation of projects and, on the other hand, they recognize the ability of local actors to manage their own resources and determine their own development.

\section{The identified limits}

Many criticisms have been levelled at participatory approaches, with regard to the inadequate consideration they give to the social contexts of approaches (Reed, 2008; Faysse 2006; Salafsky et al., 2002; Margolouis and Salafsky, 1998; Brandon and Wells, 1992). The criticisms taken into consideration with regard to the issue of including the intervention social context in ComMod approaches are the choice of participants and the results of these approaches.

\section{The choice of participants and how they express themselves}

If issues and mechanisms of social differentiation are not analysed, social inequalities are accentuated and there is a risk of one stakeholder manipulating the others (see Chapter 5). Such approaches can thus accentuate the positions of strong players in the socio-ecological system, giving significant weight to dominant players at the expense of weak or absent stakeholders. Such power asymmetry accounts for project benefits being hoarded by some local elites. The representativeness of participants is particularly questionable in situations of conflict and gives rise to confusion in the benefit of the approach in terms of the empowering of local actors. Finally, problems concerning the validity of the information gathered undermine the relevance of the solutions identified with these participants.

\section{The limits of the results of these approaches}

Any insufficient underpinning of these approaches in an institutional context has three consequences: (i) these approaches do not go much beyond the scale of community intervention, and their effects dwindle once the intervention is completed; (ii) the 
frustration of stakeholders who, having identified either the problems or the solutions to these problems, cannot solve them because of interdependencies with other regional or decision-making levels; (iii) there is a tendency not to address the actual causes of the situation but only its effects, without questioning the foundations forming the basis of inequalities and social relationships. The lack of a detailed inventory thus often leads to a risk of being unable to ensure either the inclusion of decision levels or fairer processes (Holmes and Scoones, 2000).

The issue in defining the social context is thus to provide a better definition of the implementation of the social intervention process or give consideration to the cause and effect relationships within the socio-ecological system examined. However, analysing the context involves more than just describing the territory and the stakeholders, as indicated in box 1 of Figure 4.1. It also makes it possible to define the action situation at the beginning of the project (box 2 in Figure 4.1). Did the ComMod approach arise out of a conflict, an identified problem, a territory project or a local territorial dialogue initiative? If it arose out of a conflict or a problem, who identified it and how was it qualified? In all cases, the attention given to the initiators and to the start of the process helps to provide an explicit definition of the process issues and objectives within the action situation.

\section{The ComMod context process}

The previous sections showed how conceptions of context have changed and, in particular, how the social context is now seen as heterogeneous, hierarchical and nonuniform, and how networks of interacting individuals, institutions and power asymmetry are highlighted as explanatory factors. This change helps to clarify causal relationships. Having outlined the theoretical and empirical evidence in favour of including the context in a participatory approach, the role of the socio-environmental context and intervention social context in ComMod approaches should now be considered.

\section{The tools and methods used for mainstreaming the social context in ComMod approaches}

In addition to reviewing the literature on the problem identified by the representative, for example, and the situation of the project on the ground, a few techniques and methods are commonly used in ComMod approaches to define the socio-environmental context and intervention social context (Box 4.2).

\section{Box 4.2 - The diversity of methods used in ComMod approaches to characterize the socio-environmental context and initial intervention context.}

Farming systems diagnosis with a production system entry (e.g. Mae Salaep)

Pro-active-reconciliation tool (PACT) method (e.g. Nan)

Analysis of actors (e.g. AguAloca)

Analysis of rules (land tenure, right of use and institutional analysis development (IAD) and $4 R$ (rights, responsibilities, returns, relationships) framework, e.g. Domino Réunion) 
This first involves meeting with local actors, who are initially the easiest to meet in meetings with local leaders, officials and other stakeholders, to reduce or remove any suspicion by explaining the reasons for the project (Mikkelsen, 1995). Building trust and good relationships calls for a careful choice of locations and times of such meetings so that they are as convenient as possible for stakeholders (Jackson and Ingles, 1998). Thereafter, semi-directive exploratory interviews make it possible to determine the situation, major issues and main stakeholders (Margolouis and Salafsky, 1998). Interviews with resources people who have particular knowledge of the subject and intervention field are often very enlightening even though their views may not necessarily be representative (Jackson and Ingles, 1998). Semi-directive interviews can be usefully supplemented by participant observation, field visits with resources people to determine local culture and customs and discuss the actors involved and any major changes observed (Guijt, 1999). Finally, participatory mapping with stakeholders helps to clarify the issues and interests, in particular those related to land, customs or environmental problems. The many techniques (Mikkelsen, 1995) are also involved in the analysis of actors (Grimble and Wellard, 1997; MacArthur, 1997) aimed at, on the one hand, identifying the key players in relation to a given problem, situation or particular project and, on the other, clarifying the respective interests of these actors and the nature of their interactions (Allen et al., 2002). This initial analysis thus identifies how the interests of actors are likely to affect the process outcome, either by contributing to its success or bringing it to a rapid halt (Margolouis and Salafsky, 1998). This analysis is thus part of a survey into the feasibility of implementing the approach.

An analysis of actors usually identifies the individuals, social groups and organizations whose practices or lifestyles are likely to be affected by the project. It shows who has influence or who is able to affect the project and its dynamics. This obviously includes those who are likely to go along easily with the process as well as those who are likely to oppose it. It is sometimes useful to make a distinction between the stakeholders who are likely to benefit directly from the process, those who will be involved in the process but will not necessarily benefit from it, and those who may have an interest in the outcomes of the process but who are not directly involved or concerned (Margolouis and Salafsky, 1998). What are the expectations? Why participate in the process? What are the benefits they could gain from it? What are the possible implications? What are their abilities to participate in it? What are the conflicts of interest? What are the attitudes towards other stakeholders? To these questions can be added, on the one hand, an assessment of the positive effects of the process, negative effects, neutral effects or uncertain effects on each of the identified interests and, on the other hand, a definition of the involvement priorities of actors according to their level of influence and their power, in particular as part of a strategic approach to participation.

Other analyses focus more on analysing the institutions (Ostrom et al., 1994). This type of analysis involves looking at the action situations and actors focusing on the rules in use and how they are conceived and implemented (Babin et al., 1999). Together with the institutional analysis development (IAD) developed by Ostrom et al. (1994), the 4Rs (rights, responsibilities, returns, relationships) method (Vira et al., 1998 in Barnaud, 2008) augments the analysis of the usual actors by providing information on the rights of access and use, the types and levels of responsibility in the management of resources, the returns likely to be generated by the resources, and finally the relationships with 
other stakeholders. When the project objective or problem has not been identified by the approach representative or in earlier work, it may be best, as in the approach adopted by Barnaud (2008), to make use of the pro-active-reconciliation tool (PACT) method developed by Jésus (2001). The advantage of this method is that its aim is to define precisely the problem stakeholders want to see addressed. Another advantage of this method is that it allows actors to be analysed according to their own perceptions and interactions. This may make it easier later on to analyse the effects of participatory approaches in terms of learning and negotiation on the basis of observed changes from the standpoint of the perceptions of issues and other actors and interactions, as well as how actors see the future (Jésus, 2001).

This actor analysis greatly facilitates the analysis of the initial situation and facilitates the incorporation of power games. It thus makes it possible to evaluate the feasibility of the approach and also reduces the risk of unintended effects in terms of social interaction and balance of power.

\section{Materials and methods}

In the ADD-ComMod project, the characterization of the socio-environmental context of the experiment analysed is based on the outline of each of the 27 case studies. However, the diversity of this material remains vast. Some authors included everything that was known in the field concerned so that anyone reading the outline would know what this field involved. However, most focused on what was needed to understand the implementation of the companion modelling process. This greatly limits the harmonization of data for a detailed analysis of contexts. These outlines will thus only be briefly characterized on the basis of the compilation work carried out by Étienne (2008).

Regarding the effects of context on the approach and results, 18 ComMod experiment assessment reports were available covering a wide range of materials. These outside assessments often involved a reconstruction of the process on the basis of semi-directive interviews. We conducted a survey among the designers or assessors of 13 case studies to collect more detailed information regarding the initial context and its influence in the process.

At a risk of underestimating certain aspects and overestimating the importance of others, it is stressed that, despite the lack of sufficiently accurate data gathered on the context subject, the aim was to select relevant material and not to make a value judgement on the experiment considered.

\section{A diversity of socio-environmental contexts}

The diversity of social, economic, environmental situations in which these case studies took place was highlighted. These case studies present a wide range of socioenvironmental contexts. Nearly half of them were implemented in advanced or developed countries and were a continuation of earlier research or development projects. Half of the case studies focused on natural heritage conservation issues (e.g. habitats, emblematic species and genetic diversity) or the control of natural hazards (e.g. erosion or forest fires). Eight studies focused on water management and four on problems of agricultural productivity or hunting. Three made no mention of any relationship with environmental problems. Four case studies were a direct result of an old research programme firmly 
located in a given area, seven were related to development projects and twelve were associated with the implementation of public policies. For the latter, two-thirds involved decisions taken at national level (e.g. decentralization, creation of national parks or distribution of cultivars) and one-third at local level (e.g. water management scheme or soil protection). In the last seven case studies, reference was essentially made to changes in use (e.g. agricultural abandonment or land privatization) that have led to the future of the territories concerned being put into question. Almost half the case studies concerned conflicts over access to resources or sharing a territory between economic activities, recreation and nature conservation. The other half mentioned the importance of the involvement of social groups or the method used to organize local societies in the issue concerned. Finally, five case studies focused primarily on 'traditional' practices of local actors (farming or use of water).

With regard to the scales and levels of resolutions used, half the case studies related to clearly defined territories and half to areas with undefined boundaries. According to the question raised, the organizational level adopted ranged from the most meaningful biophysical entity in the system functionality (e.g. agglomeration, river delta, catchment area or geoterritory) to administrative entities within which public policies apply or for which statistical data were available. This level can be reduced to a municipality or cover a whole department. The resolution level chosen to address the issue was highly variable and different levels were often used in a given case study, with the operating unit often used.

\section{Mainstreaming of the context effects in ComMod experiments}

This section aims to clarify the relationship between knowledge of the socioenvironmental context and intervention context and the implementation of the ComMod experiment.

\section{Diversity in the formulation of social demand in the initialization of the process}

The analysis of the 27 case studies highlighted the great diversity in the initialization of companion modelling. Of these case studies, 16 involved almost exclusively researchers, even if the work of the latter was only possible if they found allies and local go-between actors beyond academic circles. In 11 cases, institutional stakeholders were directly involved, and NGOs and associations played an active role in three studies.

Two scenarios were thus observed:

- a relatively precise request is made by a representative, often a community or a local or central authority; this representative usually has legal legitimacy to address the problem - a rather vague social request is made, without a group initially identified to deal with the issue, generally defined by a team of researchers, either within a strictly research context or associated with the implementation of public policy.

In the first case, local actors can directly ask a researcher to carry out work in connection with an issue concerning them. This was the case, for example, of the Cévennes National Park in 2000. Concerned by land abandonment and the threat 
this posed to most of the natural heritage issues identified in the Causse Méjan area, representatives of the scientific department asked a researcher to carry out a prospective analysis. This researcher then suggested the setting up of a companion modelling approach with all the local stakeholders in order to predict how this area would evolve according to various management strategies, while simultaneously including natural heritage and productivity issues and facilitating dialogue between them (Étienne et al., 2003). If the companion modelling approach is carried out successfully in response to an issue in a specific location, in certain situations there may be a spin-off through the emergence of a request for the approach to be implemented by local stakeholders. This is particularly well illustrated by the civil society experiment with land in the Larzac region following on from the success of the Causse Méjan study (see the Larzac case study). In other situations, the outcome of a case study may give rise to several organizations seeking this type of approach to be tailored to similar concerns. As a result of the SylvoPast project (Étienne, 2003), proposed in 2000 in response to a request from the Ministry of Agriculture based on forestry development and the prevention of forest fires, the agriculture and forest service of the Gard department thus asked the researcher who carried out this work to tailor this approach to the problems of forest-fire prevention at the interface between urban and natural areas (see the Nîme-Métropole case study).

In the second scenario, commodian researchers alone or in association with other researchers suggested the idea of setting up this type of approach to local stakeholders in response to a local issue identified by the researchers but also likely to mobilize local stakeholders. Researchers most often focus on a specific case connected with their research subjects. They may also be interested in implementing the approach in a country and/or in a situation that they had not encountered so far. In some studies, these two types of interest can be combined. The Mae Salaep case study, which at the beginning addressed the analysis of interactions between the risk of land degradation and agricultural diversification with the aim of reducing this risk in the future, thus enabled the researchers involved, not only to capitalize on the data from several years of fieldwork on the agrarian situation and the risk of soil erosion, but also gave them the opportunity of testing the ComMod approach in Thailand (Barnaud et al., 2006a; Trébuil et al., 2005).

Whatever the scenario described above, the respective influences of the commodian and other actors in translating a possible request into issues that can be addressed by companion modelling vary widely, particularly as the request is not always clearly expressed. In many situations, the researcher must make an effort to translate and break down the expectations of local stakeholders, and then reformulate this request jointly with stakeholders.

\section{Diversity in mainstreaming the initial context}

For three-quarters of the case studies, the initial context was mainstreamed within the approach framework (i.e. in setting objectives and selecting participants and the participatory scheme). It appears that in situations of interculturalism in poor, developing and emerging countries, the ComMod intervention was generally preceded by an initial analysis of the intervention social context often based on previous research in the same field. It frequently appeared to be detailed on biophysical functioning and local 
stakeholders, but seemed less detailed with respect to institutions and decision-making processes beyond the local level. For the remaining quarter of the case studies, no explicit consideration to the initial context was given in implementing the process. The context aspects were essentially identified during the process and gradually taken into account in activities according to the needs emerging during the various stages.

Out of the 13 case studies for which more context mainstreaming aspects were available, only two experiments did not follow on from past research or development work. One experiment resulted in a strict framework approach (a very detailed initial context study provided the main guidelines for the process), and the other a gradual approach that involved a local authority mandate.

Out of four case studies involving a community or local authority mandate, only one gradually took context into consideration, while in the other two case studies the context was considered as a guideline and in the last case study context was considered as a strict framework. When case studies were initiated by researchers, the proportion of the study in which the context was considered as a guideline changed little $(55 \%)$, but contexts providing a strict framework were higher $(33 \%)$ than for gradual cases $(11 \%)$.

When the commodian does not know the local situation or is not familiar with the issues before carrying out an initial analysis, the context provides a guideline or a strict framework. It should be noted that in three-quarters of the case studies the local situation or issues were fairly well known to the ComMod designers and coordinators and when this was not the case, a more detailed context analysis was carried out.

Thus, when the context was considered by designers or assessors to provide a strict framework in the process, a thorough initial analysis of the socio-economic context was carried out, and the analysis of stakeholders and biophysical context was well known but less detailed than the other dimensions. In processes where the context provided a guideline, the socio-environmental context was detailed but the analysis of the intervention context was very general. Finally, when the context was gradually taken into account, the process could begin without any prior knowledge of the biophysical context but in both cases there was a brief analysis of the socio-economic context. Rough monitoring/assessment of power relationships was generally implemented during the process in studies where the context provided a guideline or a strict framework.

In short, the context was mainstreamed and provided a framework for the approach in most case studies whether covered by a mandate or not. Moreover, in view of the wide range of context mainstream possibilities, the decision to define the initial context in detail (and use this knowledge to provide a framework for the approach) depends more, it would seem, on the researcher's stance (see Chapter 5) and the existence of previous studies than the researcher's familiarity with the issue or field of intervention. Note that it seems such familiarity can lead to implicit recognition of power games and power asymmetry (see Chapter 5).

Let us now try to analyse the consequences of context mainstreaming on initializing the ComMod process. However, for reasons of heterogeneity of both the initial studies and assessment reports, it was not always possible to distinguish the effects of taking the context into account on the results and approach. We thus propose to adopt the main consequences mentioned in the assessment reports where an explanatory link can be established with the fact of the context being taken into account or not. 


\section{Consequences on the definition of project objectives}

The analysis of the initial context had a significant influence on the definition of the ComMod approaches. For example, for the designers of the Domino Réunion experiment, the analysis of the initial context made it possible to carry out a true feasibility study for implementing the process. For the other cases, this type of analysis made it possible, in projects covered by a community mandate as well those instigated at the initiative of the researcher alone, to refine and reformulate project objectives, and clarify the nature of any open or latent conflicts. The Nîmes metropolitan area experiment was the only one not subject to a preliminary analysis before specifying the approach objective, although previous work carried out by a member of the project administration did in fact contribute greatly to the setting out of the issues and characterizing the main stakeholders concerned.

Despite this general observation, it appeared in several assessments that project objectives were not always clearly understood by those involved. Research projects not followed up by concrete action through a development project were often the cause of this confusion. The research and development issue is often identified upstream of a ComMod approach by or with an institutional representative or following on from a previous study. In this case, the institutional problem seemed to dominate all other issues (e.g. relations with territory, use, etc.). The approach may not always allow this initial objective to be challenged or make stakeholders true players able to define their relevant issues, and knowledge to be mobilized. In the case of the AguAloca project, for example, while neighbourhood associations were not involved in identifying the problem, they nevertheless identified new issues relating to waste management, land speculation or the financial difficulties they encountered to improve the situation.

With hindsight, it is clear from ComMod experiments that the analysis of the initial context makes it possible to identify the range of issues and problems, and realistic goals can be set for the project, thereby ensuring that it is not too ambitious, thus limiting the risk of the process failing.

\section{Impact on the choice of participants}

The identification and selection of participants is important in terms of the approach's transparency, representativeness and legitimacy. There are typically four types of participant selection (Steyaert and Lisoir, 2005):

- open on a voluntary basis: anyone who wants to participate to ensure the broadest possible involvement

- representation: selection of participants representing a standpoint, system of values or knowledge of the various stakeholder groups

- demographic: sampling to provide a representative cross-section of the population

- limitation: the number of acceptable participants given the methods and tools used.

In the outline and assessment reports, experiments were often quite vague about the criteria for selecting participants at the various stages of the approach, even when the initial context had been analysed in detail and taken into account. The participants were selected based on their knowledge of the system or for their influence on it by the researchers and institutional players running the experiment. Participants were generally invited as representatives of other actors with common interests with regard to the 
problem. These representatives, however, were often not recognized representatives designated by the actors in the same socio-professional category, for example. If the process is part of, or initiates, a group decision-making process, discussions thus need to be broadened to include all the stakeholders concerned (Barnaud, 2008).

In the case of experiments where the context provided a strict framework, as in Thailand, in particular, participants were invited on the basis of a nominative selection after a survey. Such a selection seeked to strike a balance between socio-economic categories and issue categories, but also depended on the self-expression ability of stakeholders and marginal players, in view of the local balance of power analysed in advance. The final choice of participants was then discussed between researchers and authorities. In other situations, the key players involved were mobilized through the knowledge of the representative or resources people. The actors could thus be mobilized in stages by researchers and the institutional network involved in the project (e.g. Camargue, Pays de Caux or Nîmes-Métropole case studies). When participants are selected by the researchers alone or with institutional stakeholders, the question of their representativeness needs to be raised. While the working circle can be broadened at the proposal of the experts or stakeholders invited to attend a first meeting, some choices seem questionable and have been challenged retrospectively by a few stakeholders in several projects. In the case of the Nîmes-Métropole experiment, for example, several stakeholders questioned the absence of players such as the National Forestry Commission because the socioecological system considered was of primary concern to forest management. The expertise of this institution was called for by some stakeholders but for reasons of administrative competency fields, they were not, in the end, asked to take part in the experiment. Others wondered about the overrepresentation of hunters and the fact that land planners, residents and associations did not participate in the joint conception phase.

In Brazil, as in other countries where there is a huge divide between social groups, and where wealthy individuals live alongside people living in conditions of extreme precariousness, relations between state services and populations are tainted with paternalism on the one hand and vote-catching on the other. Excluded and disaffected populations are obviously not affected. The representativeness of neighbourhood associations may also be questioned as they inherit groups set up under dictatorships for the distribution of food baskets and exert some social control. For AguAloca, the actors involved were thus primarily the institutional actors of water management structures and an environmental NGO; at Ter'aguas, representatives of municipal services, professional public health associations, NGOs and neighbourhood associations were involved. In addition, many actors adopted militant stances and were engaged in education and supported actions in favour of the disadvantaged populations living in the catchment areas. Only the most motivated and already mobilized individuals were thus involved in the project. The socially excluded were consequently not involved despite their being the primary actors concerned.

While the context analysis for the project in Tarawa focused on local stakeholders, the institutional context upstream was apparently not really considered. This was reflected in the lack of involvement of key players: government representatives, members of the Smart and Aware Pervasive Healthcare Environments (SAPHE) project steering committee and donors, who did not consider work products willing to move the project forward according to the initial timetable because of a lack of confidence of these meta-players in 
the approach. The approach designers and the assessor considered retrospectively that it would have been better to involve them to make sure they agreed with the approach and its results. Unlike this difficult situation, the Domino Réunion project identified the stakeholders on the basis of a large-scale institutional analysis. However, the team encountered difficulties in mobilizing key players for the main issues identified. On the other hand, in the case of Domino Senegal, the mobilization of key players was effective but old conflicts re-emerged in favour of debates on the legitimacy of the stakeholder representatives with discussions on the ethnic-economic dimensions of land issues.

These examples show that the question concerning the choice of participants is difficult to clarify retrospectively and remains a difficult stage in the process. Initial analysis makes it possible to identify key players, interests and potential conflicts. Although it contributes to defining the participatory scheme, it is still sometimes difficult to show a causal relationship retrospectively between the choice of participants and the analysis. The choice of participants is a trade-off between representativeness and the availability of actors. In this context, co-option is relatively frequent and occurs in networks of process researchers or representatives. In other cases, the choice to mobilize representatives of associations instead of inhabitants is often the result of a trade-off between representativeness, representation and interface with direct actors. The mainstreaming of the initial social context is important in clarifying the choices of participants but does not guarantee that such choices are the most relevant retrospectively and does not guarantee their mobilization. Despite this, it does not appear, according to the available assessments, that the ComMod processes analysed are challenged by participants. While instrumentalizing risks are mentioned, they are not, on the basis of these case studies, likely to be very tangible.

\section{Consequences on project dynamics}

The initial identification of conflicts helped to adapt the approach workflow by gradually and not necessarily simultaneously selecting participants during role-playing sessions as in the case of the work carried out in the Ter'aguas project in Brazil. The same applied in the case of Domino Réunion. While the initial study of the context had identified the players that it would be useful to involve in the model design stages, it was not possible for technical reasons to include all of them at the same time. The process thus gradually included stakeholders in various problem definition, representation and discussion workshops. This caused frustration among some participants. Moreover, the existence of divisions between some personalities representing divergent interests that were not clearly identified initially, led to an imbalance in dealing with issues in favour of the best-organized stakeholders. Similarly, but dealing with issues of water quality and water infrastructure, the interests of domestic users and small farmers were not addressed in the case of the ComMod process in South Africa (Kat Aware). The social and education level greatly influenced the involvement of local actors in this experiment. Large farmers were more familiar with the modelling and better able to discuss it. The study of the initial context had not considered these dimensions, which involve power and knowledge asymmetry. The team thus concluded that the model and role-playing were ultimately more useful in discussing the needs of large farmers rather than dealing with all the issues around the distribution of water resources. In the case of Domino Senegal, the initial analysis identified a committee 
of users on the basis of both representativeness and availability criteria. However, the players who made themselves available were not necessarily the most representative. Nevertheless, the approach made it possible to rebalance the group and include players who were initially marginalized.

In the Asian case studies, the mainstreaming of the initial context also allowed the approach to be tailored. In the case of Lingmuteychu, the initial analysis selected two villages, the conflict between which was representative of issues throughout the catchment area. The exemplarity of the first phase in the process, regarded locally as a success with these first two villages, made it possible, during a second phase, to widen the project to all the other villages in the catchment area. In the case of Nan, the initial analysis of the context provided a great deal of knowledge about the people and allowed participants to be selected with the village chief. It also established a working method to mainstream the balance of power between the national park and villagers, in other words it supported the stakeholders in a weak position compared with very influential actors and thus gradually allowed them to participate. The process was thus initiated by meetings within the village without the presence of the representatives of the national park so that the villagers could share their views on the park issue and define a strategy. Another meeting was attended by park officials, without the villagers, so that they could discuss the issue between themselves. Finally, a workshop brought together all the protagonists. Since everyone had been able to think ahead about the issue, nobody could withdraw from discussions on possible agreements on the pretext of having to discuss matters with members of their community or institution. In the case of Mae Salaep, the intervention social context was reassessed at the end of each stage and, in the same way as in Nan, made it possible to tailor the method and choice of participants in various workshops. So during the third ComMod cycle, the stakeholders representing institutions with an organization level higher than that of the village were able to be included in the process. This was done at the request of villagers who needed to be reassured (gradually during the first two cycles) prior to attending such a meeting (Barnaud, 2008). In this case study, the initial analysis also facilitated the identification of a Christian leader whose charisma and the respect the community held for him made it possible to bring together the villagers around a common project. The designers and assessors of this experiment considered that the identification and inclusion of this actor in the process, whose status and social network were such as to make him a catalyst in the change process, were instrumental in the participation of certain social groups and its success.

\section{Impact on the decision and action}

Most ComMod projects are led by researchers and are not intended to make the changes, but rather to improve the quality of the process leading to the decision to make changes in accordance with the principles of post-normal science discussed in the introduction to this book. Let us now turn to the context mainstreaming process on initializing experiments and to what is likely to facilitate the move forward to taking decisions or action.

First, it is clear from the assessments that the action arena invested or set up within the ComMod process is generally not the right forum for discussion aiming to move towards decision-taking. It is located alongside this forum, but a stakeholder learning or empowerment process is systematically required to define a new action context to include 
or create a decision forum. When processes are included in the right forum for decisiontaking, it sometimes helps to change the socio-environmental context and rules, etc.

Thus, the intervention field of some projects has been widened to other spatial perimeters or administrative levels. The Nîmes-Métropole experiment has been extended throughout the Gard department. In addition, several mayors drew up a risk prevention plan. They had already begun to think about this but the ComMod approach gave them better arguments with which to discuss the implementation of the plan. In the process at Lingmuteychu, the creation of the catchment area management institution arose from the mainstreaming of interests of the stakeholders and institutions involved. The agreement reached with the villages in conflict was considered to be exemplary and helped to extend it to other villages. In other situations, the experiment was halted because of the unwillingness of some influential players in the social system to change their practices or enter into further conflict (as in the case of Radi or Nan). In the case of Larq'asninchej, the change in the social organization level failed because the integration of new players called for new representations to be included where previously there had been local handling of the problem.

If there is no initial analysis of the context or the analysis is too sketchy, this may result in a lack of mobilization of key players or representatives of institutions whose support is needed to promote social change or the adoption of new group rules or techniques. At the same time, the identification of these key people cannot guarantee their involvement for various reasons as has been shown in different studies (e.g. Mae Salaep, Nan or Domino Réunion). In these studies, several processes showed that to change or innovate, the change stakeholder (i.e. the representative of the approach/the participants in a dialogue) needs a project that will provide a clear breakdown beyond a participatory diagnosis and possible change scenarios to clarify the action context. What action? What action status (legal, etc.)? For who is it intended? In what relational context? To affect whom? The lack of any final outcome and development projects following on from the companion project may frustrate and demobilize people by giving the impression of an unfinished process. In several experiments, it would have been appropriate to anticipate on the basis of initial analysis of context and process monitoring to keep participants mobilized as they often expressed their readiness to engage in new similar experiments. An exit strategy could have been clarified from the initialization with representatives and/ or institutions.

Overall, projects still suffer from insufficient analysis of governance structures and insufficient assessment of the abilities of decentralized, local and national institutions to come to an arrangement. There are various consequences:

- insufficient account taken of social organization levels in achieving concrete actions

- insufficient identification and/or involvement of go-between stakeholders between groups and levels of organization to mobilize actors

- change that participants identified retrospectively or intentionally or unintentionally not included in the approach as not involved at the outset.

In view of the information available to us, it does not seem possible to link in further detail an action or change to the mainstreaming of context in the process of a particular experiment. It can, however, be said that the context determines whether or not these actions (as in the Méjan example where the role-playing sessions were then translated into the implementation of a concerted local development plan that was in the pipeline). 


\section{Conclusion}

The analysis of the initial context makes it possible to define the intervention context and clarify the conditions and procedures for implementing the ComMod approach, during which a group diagnosis takes place on the problem identified by the representative and/or local stakeholders. As we have seen, the context analysis raises many issues that are not specific to the ComMod approach and which have not been fully explored in this chapter. How can an analysis of the initial context identify the factors relevant to the process? How far should the analysis of the intervention social context go? However detailed the initial analysis may be, social networks and the positions of actors will change, and the real issues are only likely to emerge during the stakeholder interaction process itself. A rough initial analysis that provides the approach coordinator with an initial baseline may seem sufficient. However, with regard to the subjects addressed in ComMod experiments, it seems essential that the researcher identifies the social dynamics taking place if he wants to understand the context of his action and its inherent issues. The ComMod approach, while asserting a general aim of creating a mechanism for group thinking around a given problem and for learning to empower stakeholders to participate in group management of resources and their territory, cannot neglect such an identification issue. The desire to contribute to social change cannot result in dominating forces and power games not being taken into account. Neglecting or giving insufficient consideration to social differentiations and local power issues creates a situation for the process to be manipulated by, or turned towards, the interests of stakeholders in social and political competition (see Chapter 5). Group decision processes are generally very context dependent and contingent on the time, people and resources available. Any action or research must thus take this account. It should not be forgotten that the issue involved is the quality of the process, in other words, an approach attentive to the relevance of its mechanism and its results in terms of local issues; the involvement of key actors in the decision-making process, appropriate dialogue forums, a concrete opportunity for each participant to influence the course of the project outcome, no significant divergence between what the project offers (in the case of an institutional sponsor outside the local community), and the aspirations of the community.

We have shown that, despite the difficulty of the exercise, mainstreaming stakeholder power games arising out of the issue considered from the start of the analysis of initial context can be useful in providing the coordinator with a better understanding of the social context and its likely effects in order to scale the process approach by providing the best possible identification of participants in the various workshops. Although the context initial analysis does not guarantee success, it does identify the political and institutional mechanisms that over and above empowering actors to influence decisions, will make it possible to change decision rules and processes and mobilize the funding needed to implement the solutions identified during the experiment or subsequent approaches.

While it is considered that legitimacy of the intervention can be established over time during the process, initial legitimacy may nevertheless be crucial to the project outcome, and raises the crucial question of the intervention social context: who is leading the project and who made the request and raised the question? Who asked stakeholders to participate, and which stakeholders? Are they representative of a particular social group? How is the researcher perceived and legitimized by the stakeholders? These issues can 
only be put into perspective if the intervention social context is sufficiently well defined to establish the explanatory causal relationships; otherwise they are pointless. Likewise, the representativeness of participants in relation to the issue raised has yet to be considered.

If the decision-making processes in a complex situation are considered to be characterized by great uncertainty regarding the facts and conflicts in the very definition of problems and social issues, how is it possible to improve decision-making with a view to improving the quality of the decision without taking the action context into account? To improve the quality of the ComMod process, the initial analysis of the intervention social context should explicitly take into account the action context involved to:

- allow the commodian team or researcher to introduce themselves, explain the project and raise the awareness of, and reassure, the stakeholders

- clarify and validate the approach's initial objectives

- draw up an inventory, in particular, to assess the process by comparing before/during/ after situations

- assess the project's feasibility in terms of risks of the actors misappropriating the approach

- ensure that the selection of participants is not disconnected from the action situation involved

- validate the relevance of the approach in decision-making (forum for interactions and results).

In questioning social relationships, the ComMod approach promotes awareness and the organization of responsibilities. It facilitates the negotiation of resource management principles by gathering and sharing information and discussing possibilities. Even though the portion of the approach and context is difficult to assess in the results and actions taken, the ComMod experiments analysed contribute in various degrees to the pluralistic management of resources and territories. 